\title{
Widening educational inequalities in adolescent smoking following national tobacco control policies in the Netherlands in 2003: a time-series analysis
}

Citation for published version (APA):

Kuipers, M. A. G., Nagelhout, G. E., Willemsen, M. C., \& Kunst, A. E. (2014). Widening educational inequalities in adolescent smoking following national tobacco control policies in the Netherlands in 2003: a time-series analysis. Addiction, 109(10), 1750-1759. https://doi.org/10.1111/add.12637

Document status and date:

Published: 01/01/2014

DOI:

10.1111/add.12637

Document Version:

Publisher's PDF, also known as Version of record

Document license:

Taverne

Please check the document version of this publication:

- A submitted manuscript is the version of the article upon submission and before peer-review. There can be important differences between the submitted version and the official published version of record.

People interested in the research are advised to contact the author for the final version of the publication, or visit the DOI to the publisher's website.

- The final author version and the galley proof are versions of the publication after peer review.

- The final published version features the final layout of the paper including the volume, issue and page numbers.

Link to publication

\footnotetext{
General rights rights.

- You may freely distribute the URL identifying the publication in the public portal. please follow below link for the End User Agreement:

www.umlib.nl/taverne-license

Take down policy

If you believe that this document breaches copyright please contact us at:

repository@maastrichtuniversity.nl

providing details and we will investigate your claim.
}

Copyright and moral rights for the publications made accessible in the public portal are retained by the authors and/or other copyright owners and it is a condition of accessing publications that users recognise and abide by the legal requirements associated with these

- Users may download and print one copy of any publication from the public portal for the purpose of private study or research.

- You may not further distribute the material or use it for any profit-making activity or commercial gain

If the publication is distributed under the terms of Article $25 \mathrm{fa}$ of the Dutch Copyright Act, indicated by the "Taverne" license above, 


\title{
Widening educational inequalities in adolescent smoking following national tobacco control policies in the Netherlands in 2003: a time-series analysis
}

\author{
Mirte A. G. Kuipers', Gera E. Nagelhout ${ }^{2,3}$, Marc C. Willemsen ${ }^{2,3}$ \& Anton E. Kunst ${ }^{1}$ \\ Department of Public Health, Academic Medical Center (AMC), University of Amsterdam, Amsterdam, the Netherlands,' Alliance Smokefree Holland, The Hague, \\ the Netherlands ${ }^{2}$ and Maastricht University/CAPHRI School for Public Health and Primary Care, Maastricht, the Netherlands ${ }^{3}$
}

\begin{abstract}
Background and Aims In 2003, the Netherlands introduced tobacco control policies, including bans on tobacco sales to minors, advertising and sponsoring and tobacco sales in government institutions. We examined the extent to which these policies were associated with a change in educational inequalities in adolescent smoking. Design Repeated cross-sectional survey. Setting The Netherlands, 1992-2011. Participants A total of 43527 14-19-year-old adolescents. Measurements Data were obtained from the national Youth Smoking Monitor. We used logistic regression analyses to model the immediate change in daily smoking prevalence in 2003, the trends and the changes in trends. Models included interactions between educational level (high versus low, based on the educational track of the respondent) and, respectively, period (after versus before 2003), time and time $\times$ period. Findings Before 2003 the smoking trend declined slightly, and the decline was comparable for students of both high and low educational levels. Immediately after tobacco policies were introduced, daily smoking prevalence dropped for the total population [regression coefficient $(\beta)=-0.340,95 \%$ confidence interval $(\mathrm{CI})=-0.445 ;-0.236$ ]. This drop was larger for high educational level compared to low educational level ( $\beta$ interaction $=-0.400,95 \% \mathrm{CI}=-0.623 ;-0.176)$. After 2003, trends in educational inequalities in smoking stabilized. Conclusions Following the introduction of new tobacco control policies in the Netherlands in 2003, smoking prevalence rates decreased among adolescents of both higher and lower educational levels. However, socio-economic inequalities in adolescent smoking increased.
\end{abstract}

Keywords Adolescents, policies, smoking, socio-economic inequalities, the Netherlands, tobacco control.

Correspondence to: Mirte A. G. Kuipers, Department of Public Health, Academic Medical Center (AMC), University of Amsterdam, PO Box 22660, 1100 DD Amsterdam, the Netherlands. E-mail: m.a.kuipers@amc.uva.nl

Submitted 24 October 2013; initial review completed 14 January 2014; final version accepted 27 May 2014

\section{INTRODUCTION}

In many European countries, differences in mortality between lower and higher socio-economic groups are, to a considerable extent, attributable to differences in smoking prevalence between these groups [1]. Both a higher observed quit ratio in higher socio-economic groups and an increased risk of smoking initiation in lower socio-economic groups result in socio-economic inequalities in smoking prevalence in adults [2]. Inequalities have been observed previously in adolescents in several monitoring surveys, with adolescents in lower educational levels being more likely to smoke than their more highly educated peers [3,4]. If we obtain a better understanding of how to reduce socio-economic inequalities in adolescent smoking, future inequalities in mortality may be largely preventable.

An important public health approach to tobacco control is the introduction of national-level legislation [5]. In 1990, the Dutch national government took political action by adopting the Tobacco Act, which included restrictions on tobacco sales, advertising, sponsoring and smoking in public places [6]. The Tobacco Act has been amended since then. In 2003, major changes were made that were potentially important for young people: (i) a ban on sales to minors (below the age of 16 years), (ii) a ban on the sale of small packs (with fewer than 19 cigarettes), (iii) a full ban on advertisement and sponsoring and (iv) a ban on tobacco sales in government institutions [6]. Furthermore, three national mass media campaigns 
were launched that aimed to (i) encourage adults to quit smoking, (ii) educate adults on the importance of nonsmoking role models for children and (iii) discourage smoking in work-places. Campaigns were implemented at the end of 2003, preceding the smoking ban in workplaces and public transport, which went into effect in January 2004.

The effects of these policy measures on socioeconomic inequalities in adolescent smoking are not clear. A ban on tobacco sales to minors may decrease socio-economic differences in youth smoking. A national study in the United States showed that stronger state-level tobacco policies on sales to minors were associated with a lower likelihood of smoking initiation among females of low socio-economic status (SES), but not for their higher SES counterparts [7]. However, in the United Kingdom, increasing the age for the legal purchase of tobacco from 16 to 18 years of age had similar effects on smoking prevalence in both adolescents with lower and higher SES [8]. This finding suggests a neutral effect on inequalities in smoking.

Studies on the differential SES effects on tobacco industry marketing have shown heterogeneous results. A retrospective observational study showed that an increase in the tobacco marketing budget was associated with an increase in smoking initiation in the 1980s, especially in adolescents with lower educational attainment [9]. Tobacco marketing via the design of cigarette packages is unlikely to impact upon the socio-economic inequalities in smoking, as various pack designs (including plain packs) evoked similar reactions in young women with both low and high levels of education [10]. A third study showed that when an advertising ban was in place, outdoor tobacco advertising density was highest in neighbourhoods with low median incomes [11]. This suggests that a ban on outdoor advertising may be less effective among lower socio-economic groups.

There is little evidence for differential effects of mass media campaigns to prevent adolescents from taking up smoking. Vallone et al. [12] found that, in the United States, adolescents in lower-income neighbourhoods were less aware of the truth ${ }^{\circledR}$ campaign than respondents from higher-income neighbourhoods. However, the persuasiveness of the message was independent of SES in those who were aware of the campaign.

Mixed results were found in studies that evaluated multiple policies. In Finland, policies introduced in the 1970s appeared to have had stronger protective effects on higher SES young males and young lower SES females [13]. However, results from Canada [14] and Australia [15] suggest equal effects for adolescents from both low and high socio-economic groups.

Based on the knowledge available from existing studies, it is hard to predict the effects of the package of policies implemented in 2003 in the Netherlands. The evaluation of this policy package offers a unique opportunity to add evidence to the scant existing literature. Knowledge on the effects of policies in the Netherlands could be valuable to our understanding of tobacco control, not only in the Netherlands but also in other countries.

In this study, we aimed to evaluate the effects of tobacco control policies introduced in the Netherlands in 2003 on adolescent smoking inequalities. Due to the availability of continuous survey data over 20 survey years, we were able to analyse time trends and quantify changes in socio-economic smoking inequalities. We studied the extent to which the package of policies is associated with a change in socio-economic inequalities in adolescent smoking, and were interested in the differences between males and females, and younger and older adolescents.

\section{METHODS}

\section{Study population}

The 43527 adolescents included in the study population were aged 14-19 years and were enrolled in an educational institution. Data were obtained from the Dutch national Youth Smoking Monitor ('Roken Jeugd Monitor', or RJM) for all years between 1992 and 2011. The RJM is an annual survey that at the time was commissioned by STIVORO (the former Dutch Expert Centre on Tobacco Control) and was carried out by TNS NIPO (a Dutch survey agency) among 10-19-year-old adolescents. For this study, we excluded the ages 10-13, as most students in this age group have not yet entered a specific educational track (part of the Dutch education system). From 1992 to 1994, respondents were interviewed personally near their schools, using a paper questionnaire. From 1995 onward, interviews were conducted on school premises using computer-assisted personal interviewing (CAPI).

Trained interviewers recruited a quota of respondents, defined in terms of educational track, gender and age. Each interviewer visited schools in their own region, interviewing a minimum of two classes per school. A maximum of 20 students were interviewed per school, and a maximum of five students per class. The schools were selected by interviewers based on convenience; schools were not sampled randomly out of all schools in the Netherlands. Interviewers were based throughout the country in order to ensure sufficient geographical distribution, including representation of all provinces in the Netherlands. Each respondent was given an individual sampling weight (based on age, gender, school type and province of residence) to represent the Dutch adolescent population (based on data provided by Statistics Netherlands). 


\section{Variables}

The questionnaire included three questions on smoking frequency: 'Have you ever smoked?', 'Have you smoked in the past four weeks?' and 'Do you usually smoke every day, one or more times a week, or less than once a week?'. We defined daily smokers as respondents who had smoked in the past 4 weeks and who indicated that they usually smoke every day.

Lower and higher educational levels were distinguished. In the Dutch educational system secondary school students choose between three main school tracks, usually at age 13 or 14 (2nd or 3rd grade). Selection is based mainly on cognitive abilities of students, estimated by teachers, parents and students. Students start secondary school at age 12 and, depending on which of the three tracks they choose (low-, intermediate- or highlevel), leave secondary school at age 16,17 or 18 , respectively. The low-level track prepares for lower vocational education, the intermediate-level track prepares for higher vocational education (Bachelor's degree), and the high-level track prepares for university education (Master's degree). In this study, 'lower' educational level was defined as attending low-track secondary education or lower vocational education, while 'higher' educational level was defined as attending intermediate or high-track secondary education, higher vocational education or university. The attended educational level was considered an indicator for socio-economic status of adolescents, as it largely determines educational attainment in later life.

Gender, age (in years) and household size (number of people living in the home) were also measured. The year of the interview denoted time.

For smoking, gender, age and year of the interview there were no missing values. Respondents with missing data on household size $(0.4 \%)$ and educational level $(12.8 \%)$ were excluded. Students who did not yet enter a specific educational track $(8.3 \%)$ were also excluded, as they could not be classified in terms of high or low educational level.

\section{Statistical analyses}

We used a segmented time-series design based on methods used by Federico and colleagues [16]. The segments studied were the period before and after 1 January 2003, when most policies were implemented. Time was therefore centred around $2003(2003=0,2004=1$, etc.).

Logistic regression analyses were applied. We were unable to use multi-level modelling, because information on class and school was not registered in the data. Moreover, a maximum of 20 students per school and a maximum of five students per class were interviewed, which reduced the extent to which clustering may have occurred.

Five regression models estimated separate slopes as well as separate intercepts for the two periods and the two educational levels in a stepwise manner. Daily smoking was the dependent variable in all regression models. Model 1 included the time in years and educational level, estimating the overall trend in smoking over the years, and the difference between respondents with higher and lower educational levels. Respondents with a lower educational level were defined as the reference group. Model 2 added the variable for period, with the period before 2003 as the reference. The coefficient for period estimates the difference in the odds of smoking in the period after 2003 compared with before 2003. The coefficient therefore showed the immediate change in smoking prevalence after the introduction of the policies. In model 3, interaction between period and time was introduced. The regression coefficient for this interaction term estimates the change in the trend after 2003 compared with the trend before 2003. Interaction between educational level and time was added in model 4 to estimate the difference in the smoking trend between respondents of high and low educational levels. Model 5 added interaction between educational level and period to estimate the difference between educational levels in the immediate change in prevalence after 2003. Finally, model 5 included a three-way interaction between educational level, period and time, which estimates whether the change in trend (before and after 2003) was different for the educational levels.

All models controlled for age, gender and household size. In a sensitivity analysis, we also controlled for the potential influence of tobacco price by adding the absolute price of a pack of the most popular brand of cigarettes (in euros) to model 5. Analyses were performed separately for males and females, and for those aged 14-15 and 16-19 years. All analyses were weighted by age, gender, school type and province of residence. Analyses were performed in Stata (version 11.0) and graphs were created in $\mathrm{R}$ (version 2.15.1).

\section{RESULTS}

Table 1 provides an overview of the characteristics of the study population, stratified by time-period and educational level. The study population after 2003 was older than the study population before 2003, and respondents of lower educational level were younger than those of higher educational level. Males and females were distributed equally over both periods and educational levels. Daily smoking was more prevalent among those of lower educational level, and prevalence rates were higher before 2003 than after 2003. 
Table 1 Description of the study population stratified by time period and educational level.

\begin{tabular}{|c|c|c|c|c|c|c|}
\hline & \multicolumn{3}{|c|}{ Period before 2003 policies } & \multicolumn{3}{|c|}{ Period after 2003 policies } \\
\hline & \multirow[b]{2}{*}{ Total } & \multicolumn{2}{|c|}{ Educational level } & \multirow[b]{2}{*}{ Total } & \multicolumn{2}{|c|}{ Educational level } \\
\hline & & Lower & Higher & & Lower & Higher \\
\hline$n$ & 25686 & 15255 & 10431 & 17841 & 10180 & 7661 \\
\hline Age $($ mean \pm SD $)$ & $16.3 \pm 1.64$ & $16.1 \pm 1.60$ & $16.6 \pm 1.66$ & $16.7 \pm 1.64$ & $16.6 \pm 1.58$ & $16.8 \pm 1.71$ \\
\hline Age $(\%<16$ years $)$ & 35.6 & 40.5 & 28.5 & 27.5 & 27.2 & 27.9 \\
\hline Gender ( $\%$ male $)$ & 50.2 & 51.5 & 48.3 & 50.1 & 50.8 & 49.1 \\
\hline Household size (mean \pm SD) & $4.24 \pm 1.27$ & $4.32 \pm 1.24$ & $4.12 \pm 1.30$ & $4.18 \pm 1.34$ & $4.27 \pm 1.29$ & $4.05 \pm 1.39$ \\
\hline Smoking (\% daily smokers) & 29.4 & 34.0 & 22.6 & 22.4 & 29.3 & 13.2 \\
\hline
\end{tabular}

$\mathrm{SD}=$ standard deviation

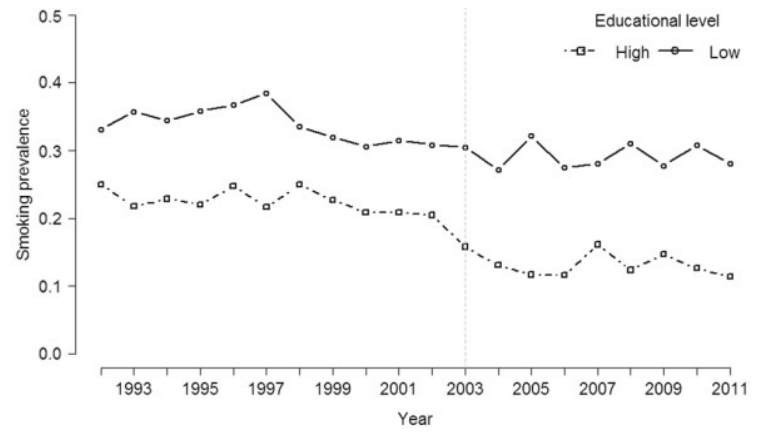

Figure I Prevalence of daily smoking among 14-19-year-old adolescents, stratified for educational level, weighted for gender, age, school level and province of residence

Figure 1 presents the smoking trends for respondents with higher and lower educational levels over the years. Over the entire length of time, the prevalence was higher among adolescents of lower educational level than among those of higher educational level. In both groups, the prevalence decreased over time. Prevalence rates for adolescents of higher and lower educational level were most similar in 1998. The most pronounced decreasing trend occurred among the adolescents in higher educational levels in the early 2000s.

Table 2 presents the results of the regression analyses for the total population. Model 1 shows that there was a declining trend in daily smoking $[b=-0.031,95 \%$ confidence interval $(\mathrm{CI})=-0.035$ to -0.027$]$, and that respondents of higher educational levels are less likely to smoke than their low educational-level peers ( $b=-0.771,95 \% \mathrm{CI}=-0.824$ to -0.719$)$. The coefficient for period in model 2 shows that there was a significant immediate decrease in smoking after 2003 $(b=-0.342,95 \% C I=-0.444$ to -0.241$)$. The nonsignificant interaction terms of time $\times$ period in models 3 and 4 indicate that trends in smoking before and after 2003 were comparable, and that no significant change in trend has occurred. In model 4, the slope of the trend was more negative for respondents of higher educational levels than those of lower educational levels $(b=-0.019$, $95 \% \mathrm{CI}=-0.028$ to -0.010 ), and educational differences in smoking therefore seem to have increased over time. However, this interaction was no longer significant in model 5.

As presented in model 5, in Table 2, a significantly larger immediate decrease in smoking prevalence after 2003 occurred in the low educational-level group compared with the high educational-level group $(b=-0.751,95 \% \mathrm{CI}=-1.275$ to -0.227$)$. The modelled prevalence before 2003 (derived from model 5) decreased by $40 \%$ in the high educational level respondents compared with $14 \%$ in the low educational level respondents.

Figure 2 presents the results for model 5 in a graph. The larger drop in smoking prevalence among respondents of higher educational level in 2003 caused educational inequalities in smoking to be larger after 2003 than beforehand. Among the respondents of both high and low educational levels, the smoking trend scarcely changed after 2003 compared with before 2003. After 2003, smoking rates among less educated respondents did not decline faster than among those of a higher educational level, and the educational inequalities in smoking therefore remained larger than before 2003.

Figure 3 and Table 3 stratify the analyses by gender. The educational difference in the drop in smoking prevalence after 2003 was larger among males than among females (Fig. 3), although this difference was not statistically significant. In females, the educational difference in this drop was not significant (Table 3), due to a larger drop among females in lower educational levels than among males in lower educational levels. After 2003, the seemingly converging and diverging trends among males and females, respectively, were not statistically significant. However, this result suggests that the gap between 


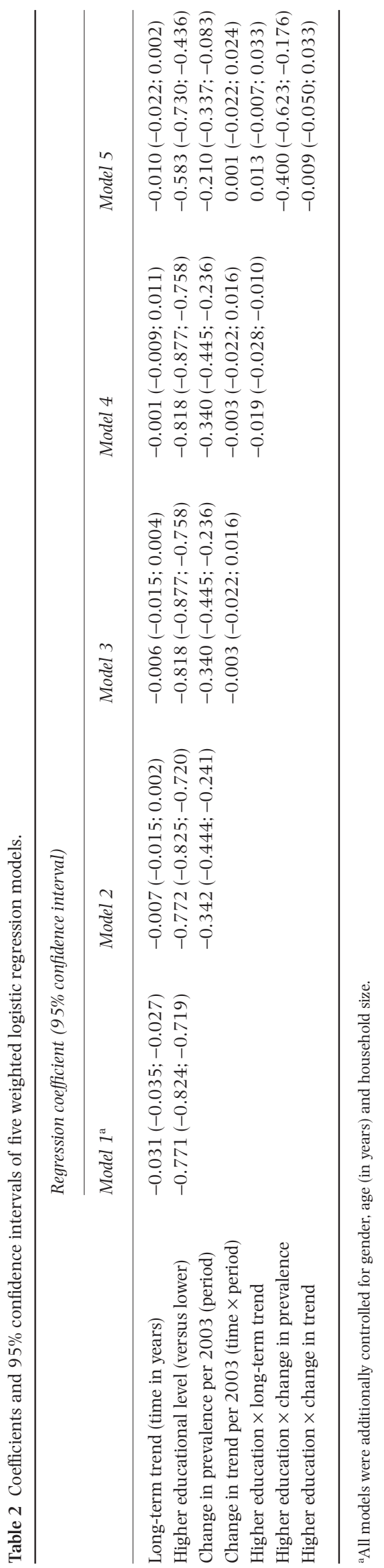

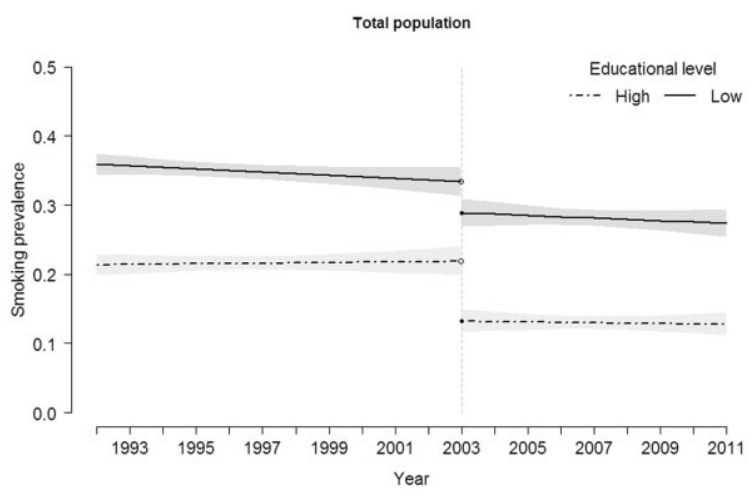

Figure 2 Linear trends in smoking before and after 2003, for the total population, adjusted for age, gender and household size

educational levels may narrow over time for males, and widen further for females (Fig. 3).

Figure 4 and Table 3 show stratified results for age groups, distinguishing between those aged $<16$ years and those aged $\geq 16$ years. The educational difference in the drop in smoking prevalence after 2003 was larger among the 14-15-year-olds than among the 16-19-year-olds (Fig. 3), although this was not a significant difference. In both age groups educational differences increased significantly in 2003 and remained more or less stable over time in the period after 2003 (Fig. 3).

No time lag effect was assumed in the analyses presented. We performed a sensitivity analysis to investigate whether the effects of the 2003 policies had a 1-year lag time. We distinguished periods before and after 2004, with time centred around 2004. In model 5, although the difference between educational levels in the immediate drop in prevalence after $2004(b=-0.306,95 \%$ $\mathrm{CI}=-0.537$ to -0.075 ) was smaller than after 2003 $(b=-0.400,95 \% \mathrm{CI}=-0.623$ to -0.176$)$, it remained significant (results not shown).

In a sensitivity analysis, we explored the influence of tobacco price on smoking and the above-mentioned results. The tobacco price remained almost unchanged around 2003, although a more substantial increase took place in 2005. Price showed little to no association with adolescent smoking prevalence $(b=-0.006,95 \%$ $\mathrm{CI}=-0.246$ to 0.234 ). Adding price to model $5 \mathrm{did}$ not change the results presented above, including the observed changes in educational inequalities in smoking in 2003.

\section{DISCUSSION}

\section{Key results}

Directly after the introduction of a comprehensive set of tobacco policies in 2003, the prevalence of daily smoking dropped among adolescents of both higher and lower 

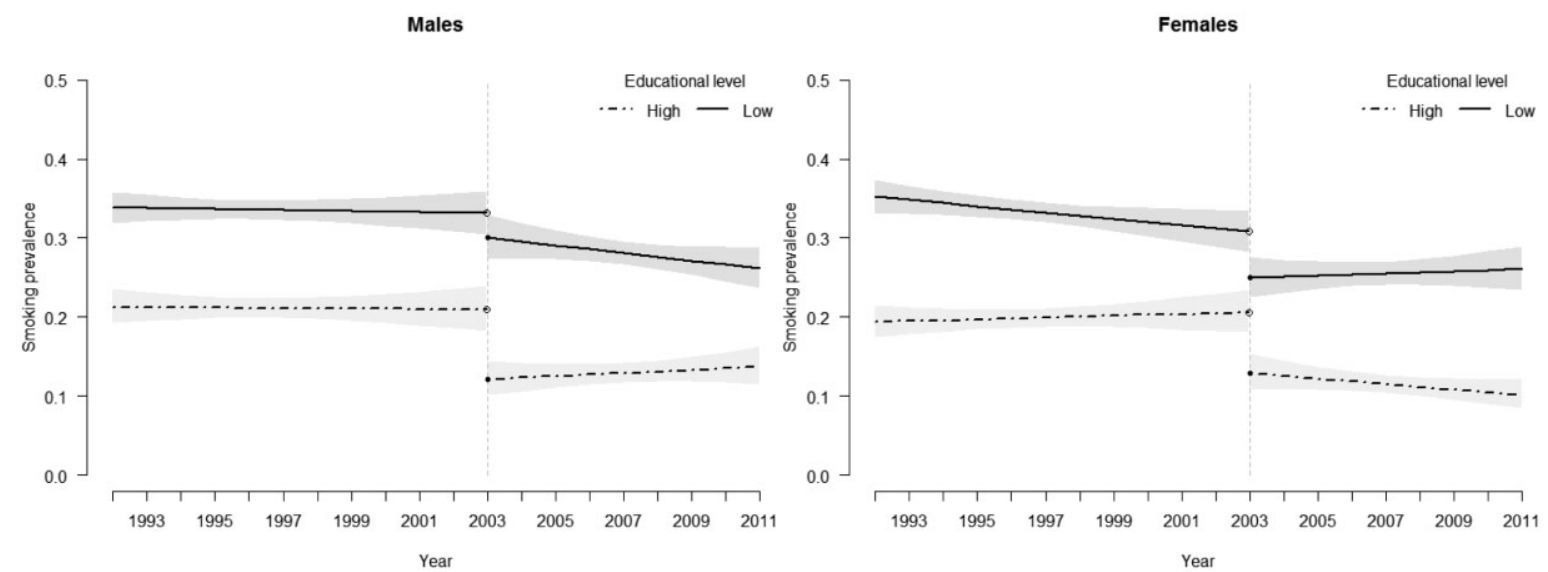

Figure 3 Linear trends in smoking before and after 2003, stratified by gender, adjusted for age, gender, and household size

educational levels; however, the drop was larger among respondents of a higher educational level. Changes in Dutch tobacco control policies in 2003 therefore seem to have been effective in both educational groups, but were also associated with an increase in socio-economic inequalities in adolescent smoking. The increase in smoking inequality was comparable for males and females and 14-15-year-olds and 16-19-year-olds. The trends after 2003 were virtually parallel, suggesting no catch-up effect for adolescents of low educational level in the short term.

\section{Evaluation of potential data limitations}

The RJM did not use a random sampling method for selecting schools and individual respondents. Groups with easier access and who were more willing to participate might have been more likely to be selected. Respondents with easier access may have been less likely to smoke [17] and more likely to be of a higher educational level [18]. However, RJM data were weighted for various demographics according to available national data. Furthermore, we compared the smoking rates in the RJM with the Dutch data from the European Survey Project on Alcohol and Drugs (ESPAD). ESPAD data are collected using a clustered random sample method. The smoking prevalence among respondents in a lower educational level was higher in the RJM data than in the ESPAD data, while prevalence rates among those in a higher educational level were comparable [19]. The RJM data may have over-estimated inequalities in smoking. However, there is little reason to assume that the trend estimates were biased, as the two surveys showed a similar decline in smoking after 2003. Furthermore, the RJM sampling method was consistent over time, and the results for trends within groups are therefore considered reliable.

The prevalence of smoking may have been underreported due to socially desirable reporting for questions concerning smoking [20,21]. Personal interviews may have resulted in more socially desirable reporting than paper-and-pencil or web-based questionnaires [21]. Adolescents of higher educational level are usually more aware of the negative consequences of smoking [22], and social desirability may therefore have played a larger role in this group. However, the sudden declines in smoking in 2003 and the subsequent increase in smoking inequalities are unlikely to have been biased by socially desirable reporting, unless we assume a sudden increase of underreporting in respondents of higher educational levels.

The effect of tobacco control policies is not only dependent upon the adoption of a national legislation, but also on the implementation and enforcement of the rules [23]. If the studied policies have not been implemented and enforced at an adequate level, our results may be an under-estimation of the potential effects. In autumn 2003, the Netherlands Food and Consumer Product Safety Authority concluded that not all tobacco control policies introduced were sufficiently implemented and enforced [24]. For example, even though 98\% of tobacco retailers said that they knew that tobacco may only be sold to individuals of 16 years and older, $90 \%$ of 13-15-year-old adolescents reported being able to buy tobacco products [24]. We have no information on whether problems with implementation and enforcement were different for respondents in lower and higher educational levels. If such differences did occur, they could have contributed to widening socio-economic inequalities in adolescent smoking after 2003.

In this evaluation we studied a package or cluster of policies, and it was not possible to separate the effects of individual policies in the study design applied. A recurrent problem in studies on the impact of national tobacco control policies is the inability to unravel the effects of separate tobacco control measures that come into effect at the same time [25]. Therefore, we are unable to draw conclusions on the effects of individual policy measures. 


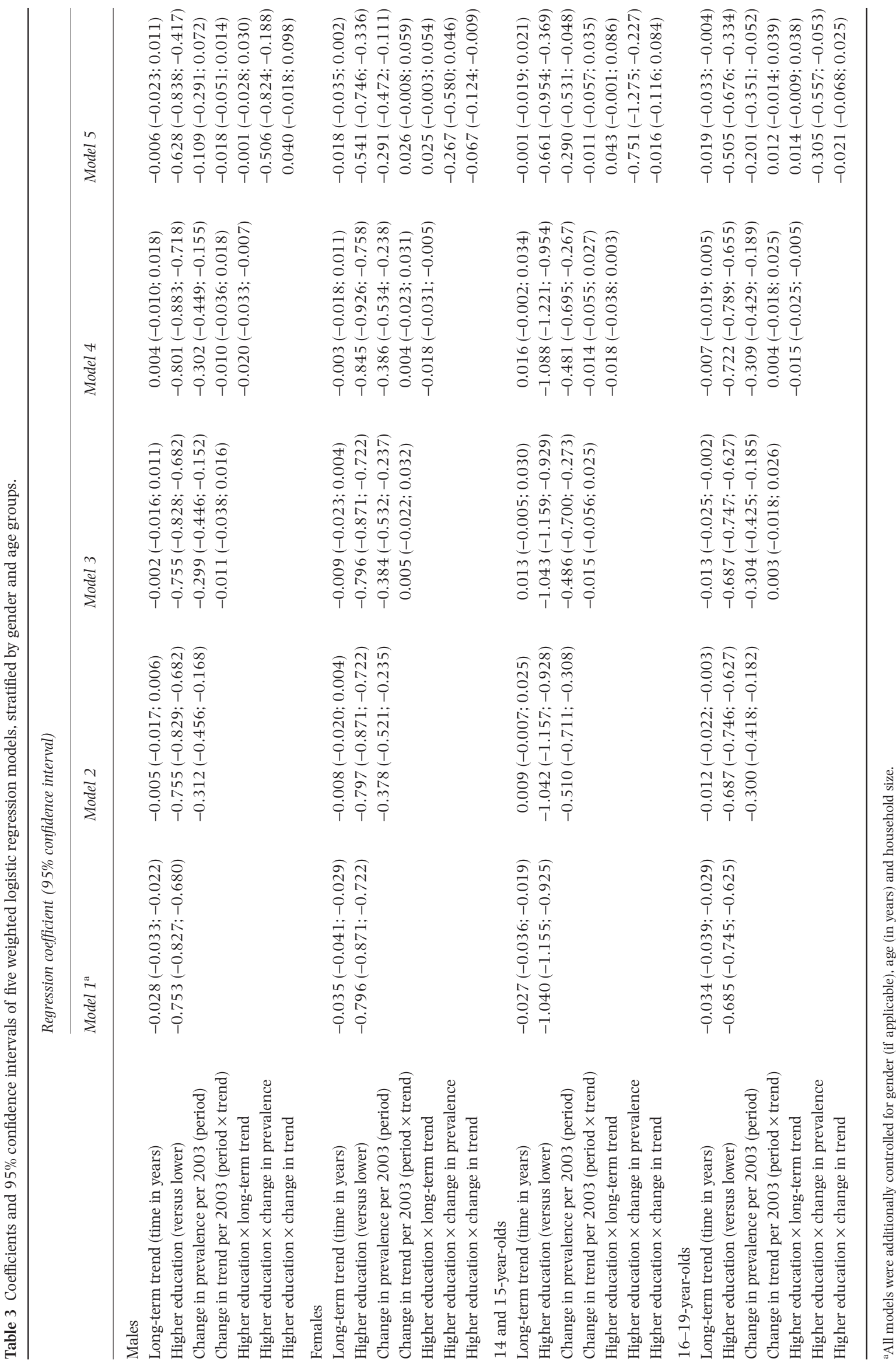



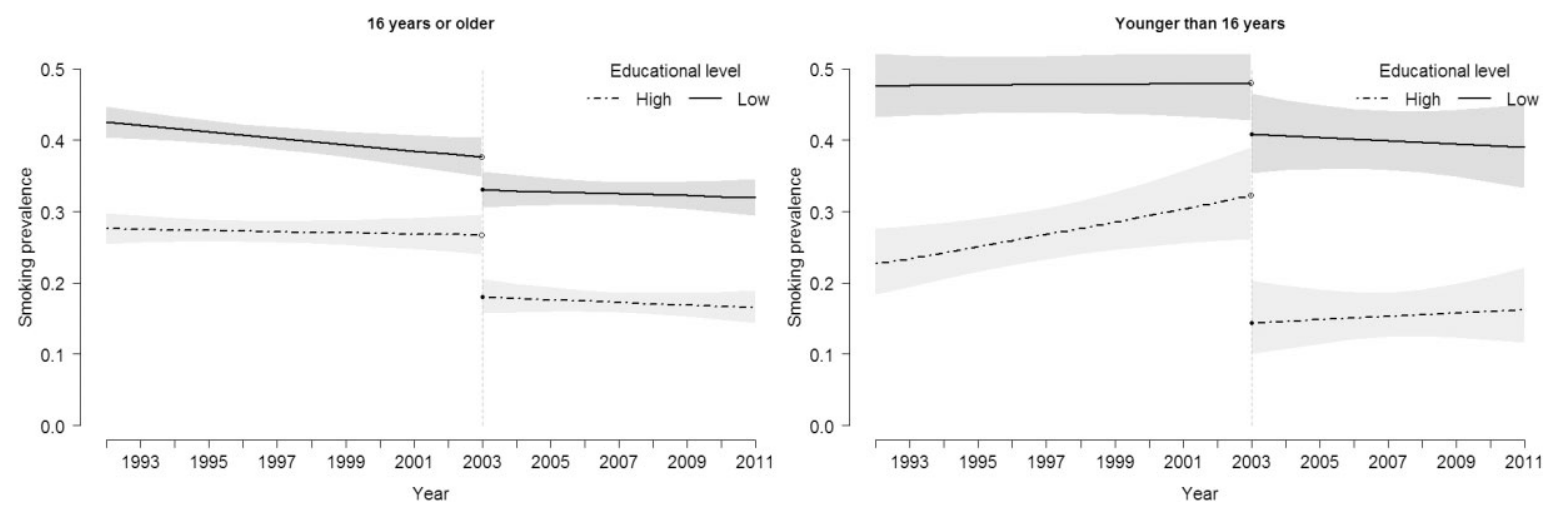

Figure 4 Linear trends in smoking before and after 2003, stratified by age groups, adjusted for age, gender and household size

None the less, the current assessment of multiple policies remains important, because it has been argued that a combination of comprehensive tobacco control policies (as summarized in the MPOWER package [23]) has the highest potential impact.

\section{Explaining results}

The 2003 tobacco control policies were associated with a smaller decrease in smoking prevalence among respondents of a lower educational level compared with their high educational-level peers. Our data do not show what caused this differential effect. Mass media campaigns may be less effective among low SES individuals [26-28], and the campaigns that were conducted in 2003 may have been most beneficial to adolescents of high educational level and their parents. Furthermore, adolescents of lower educational level may have other or more effective ways of accessing tobacco, despite the ban on sales to minors. Cigarettes might have been more easily available to lower SES adolescents, as they are more likely to have parents and friends who smoke [29].

The social environment is an important determinant of the smoking behaviour of adolescents [29]. Social environmental exposures that lead to smoking behaviour may be stronger among adolescents of lower educational level [22], as they are more likely to live with adult smokers and to be involved with peer smokers [29]. A study from Finland suggested that adolescents with low school achievement perceived their peers as having greater social influence with regard to smoking [30]. Moreover, their skills for abstaining from smoking when peer pressure was perceived were less well developed [30]. Stronger influences from the social environment may have weakened the effect of changes in the wider environment induced by new tobacco control measures.

Adolescents in a lower socio-economic position report poor mental health more often [31,32], due possibly to more stressful and difficult lives, financial strain and poorer living conditions [33,34]. Poor mental health is associated with increased smoking rates among youth [35] and might contribute to the association between SES and smoking. However, studies on the role of mental health showed mixed results [36,37]. For the present study, it is important that among those with poor mental health and stressful lives, tobacco control policies might have less impact on smoking behaviour. If so, this may have contributed to differential effects of tobacco control policies between groups of varying educational level.

Because parental smoking is an important predictor of adolescent smoking [29,38], trends in smoking in adolescents may follow the trends in adults. Therefore, it is of interest whether adult smoking prevalence rates declined rapidly before 2003. According to Nagelhout et al. [39], there was no such decline between 2001 and 2003. Later decline in adult smoking followed the introduction of a smoking ban in work-places in 2004 [40]. However, these effects did not precede the decline observed in adolescents in 2003.

Educational differences in the effects of tobacco control policies were larger for younger adolescents than for adolescents aged 16 years and over. The implemented ban on tobacco sales to minors below the age of 16 may, in part, explain the difference found between younger and older adolescents. Adolescents aged 14 and 15 years may have had more limited access to cigarettes due to the age limit for tobacco sales at 16 years. Respondents in lower educational levels may have had better access to cigarettes via their network of friends and siblings. However, previous studies observed only a moderate effect of this policy measure on adolescent smoking [41], and even suggested a stronger effect in low SES individuals [7]. Another explanation may be found not in accessibility through the social network, but in the smoking behaviour of peers. An American study suggested that peer smoking has greater predictive value in older adolescents than in younger ones [42]. 


\section{CONCLUSIONS}

National tobacco control policies introduced in 2003 seem to have had an impact upon smoking among adolescents in higher as well as lower educational levels. However, the results suggest that the policies were much less effective among adolescents in lower educational levels. This has resulted in larger smoking inequalities after 2003 compared with the decade before 2003.

Despite this increasing gap in smoking between socio-economic groups, tobacco control policy seems to be highly effective in preventing youth smoking in national populations at large. Further development of such policies world-wide is a crucial step in reducing the damage caused by smoking. The differential effects of tobacco control policies need to be studied further to clarify how policies can be made just as effective among low SES adolescents as they are among their high SES peers.

\section{Declaration of interests}

None.

\section{Acknowledgements}

The authors wish to thank Wim Busschers for advice on and assistance with the statistical analyses. Furthermore, the authors wish to thank all partners of the SILNE project for feedback on early drafts of the paper. This paper is a deliverable within the SILNE Project ('Tackling socioeconomic inequalities in smoking: Learning from natural experiments by time trend analyses and crossnational comparisons') and was supported by the European Union's Seventh Framework Programme for Research and Technological Development (FP7) [grant no. 278273-2].

\section{References}

1. Jha P., Peto R., Zatonski W., Boreham J., Jarvis M. J., Lopez A. D. Social inequalities in male mortality, and in male mortality from smoking: indirect estimation from national death rates in England and Wales, Poland, and North America. Lancet 2006; 368: 367-70.

2. Gilman S. E., Abrams D. B., Buka S. L. Socioeconomic status over the life course and stages of cigarette use: initiation, regular use, and cessation. J Epidemiol Community Health 2003; 57: 802-8.

3. van Dorsselaer S., Zeijl E., van den Eeckhout S., ter Bogt T., Vollebergh W. HBSC 2005: gezondheid en welzijn van jongeren in Nederland [HBSC 2005: health and well-being of young people in the Netherlands]. Utrecht: TrimbosInstituut; 2012.

4. Huisman M., Kunst A. E., Mackenbach J. P. Inequalities in the prevalence of smoking in the European Union: comparing education and income. Prev Med 2005; 40: 756-64.
5. World Health Organization. WHO Framework Convention on Tobacco Control. Geneva: World Health Organization; 2003.

6. Tobacco Act, BWBR0004302, Ministry of Health WaS (1990).

7. Kim H., Clark P. I. Cigarette smoking transition in females of low socioeconomic status: impact of state, school, and individual factors. J Epidemiol Community Health 2006; 60: 13-9.

8. Millet C., Tayu Lee J., Gibbons D. C., Glantz S. A. Increasing the age for the legal purchase of tobacco in England: impacts on socio-economic disparities in youth smoking. Thorax 2011; 66: 862-5.

9. Gilpin E. A., Pierce J. P. Trends in adolescent smoking initiation in the United States: is tobacco marketing an influence? Tob Control 1997; 6: 122-7.

10. Hammond D., Doxey J., Daniel S., Bansal-Travers M. Impact of female-oriented cigarette packaging in the United States. Nicotine Tob Res 2011; 13: 579-88.

11. Pucci L. G., Joseph H. M. Jr, Siegel M. Outdoor tobacco advertising in six Boston neighborhoods. Evaluating youth exposure. Am J Prev Med 1998; 15: 155-9.

12. Vallone D. M., Allen J. A., Xiao H. Is socioeconomic status associated with awareness of and receptivity to the truth campaign? Drug Alcohol Depend 2009; 104: S115-20.

13. Helakorpi S., Martelin T., Torppa J., Vartiainen E., Uutela A., Patja K. Impact of the 1976 Tobacco Control Act in Finland on the proportion of ever daily smokers by socioeconomic status. Prev Med 2008; 46: 340-5.

14. Pabayo R., O'Loughlin J., Barnett T. A., Cohen J. E., Gauvin L. Does intolerance of smoking at school or in restaurants or corner stores decrease cigarette use initiation in adolescents? Nicotine Tob Res 2012; 14: 1154-60.

15. White V. M., Hayman J., Hill D. J. Can population-based tobacco-control policies change smoking behaviors of adolescents from all socio-economic groups? Findings from Australia: 1987-2005. Cancer Causes Control 2008; 19: 631-40.

16. Federico B., Mackenbach J. P., Eikemo T. A., Kunst A. E. Impact of the 2005 smoke-free policy in Italy on prevalence, cessation and intensity of smoking in the overall population and by educational group. Addiction 2012; 107: 1677-86.

17. McCormick L. K., Crawford M., Anderson R. H., Gittelsohn J., Kingsley B., Upson D. Recruiting adolescents into qualitative tobacco research studies: experiences and lessons learned. J School Health 1999; 69: 95-9.

18. Torvik F. A., Rognmo K., Tambs K. Alcohol use and mental distress as predictors of non-response in a general population health survey: the HUNT study. Soc Psychiatry Psychiatr Epidemiol 2012; 47: 805-16.

19. Verdurmen J., Monshouwer K., van Dorsselaer S., Lokman S., Vermeulen-Smit E., Vollebergh W. Jeugd en riskant gedrag 2011 [Youth and risk behaviour 2011], Kerngegevens uit het peilstationonderzoek scholieren [Key data from the student monitoring survey]. Utrecht: Trimbos Netherlands Institute of Health and Addiction; 2012.

20. Ogan C., Karakus T., Kursun E. Methodological issues in a survey of children's online risk-taking and other behaviours in Europe. J Child Media 2013; 7: 133-50.

21. Krumpal I. Determinants of social desirability bias in sensitive surveys: a literature review. Qual Quant 2013; 47: 2025-47.

22. David A., Esson K., Perucic A. M., Fitzpatrick C. Equity, Social Determinants and Public Health Programmes. Geneva: World Health Organization; 2010. 
23. World Health Organization. WHO report on the global tobacco epidemic, 2008: The MPOWER package. Geneva: World Health Organization; 2008.

24. Netherlands Food and Consumer Product Safety Authority. VWA Evaluatie van de handhavingervaring van de Tabakswet 2002-2004 [Evaluation of the perceived enforcement of the Tobacco Act 2002-2004]. 2005.

25. Chapman $S$. Unravelling gossamer with boxing gloves: problems in explaining the decline in smoking. BMJ 1993; 307: 429-32.

26. Farrelly M. C., Niederdeppe J., Yarsevich J. Youth tobacco prevention mass media campaigns: past, present, and future directions. Tob Control 2003; 12: i35-47.

27. Niederdeppe J., Fiore M. C., Baker T. B., Smith S. S. Smokingcessation media campaigns and their effectiveness among socioeconomically advantaged and disadvantaged populations. Am J Public Health 2008; 98: 916-24.

28. Niederdeppe J., Kuang X., Crock B., Skelton A. Media campaigns to promote smoking cessation among socioeconomically disadvantaged populations: what do we know, what do we need to learn, and what should we do now? Soc Sci Med 2008; 67: 1343-55.

29. de Vries H., Engels R., Kremers S., Wetzels J., Mudde A. Parents' and friends' smoking status as predictors of smoking onset: findings from six European countries. Health Educ Res 2003; 18: 627-36.

30. Pennanen M., Haukkala A., de Vries H., Vartiainen E. Academic achievement and smoking: is self-efficacy an important factor in understanding social inequalities in Finnish adolescents? Scand J Public Health 2011; 39: 714-22.

31. Amone-P'Olak K., Burger H., Ormel J., Huisman M., Verhulst F. C., Oldehinkel A. J. Socioeconomic position and mental health problems in pre- and early-adolescents: the TRAILS study. Soc Psychiatry Psychiatr Epidemiol 2009; 44: 231-8.

32. Meltzer H., Gatward R., Goodman R., Ford T. Mental health of children and adolescents in Great Britain. Int Rev Psychiatry 2003; 15: 185-7.
33. Wadsworth M. E., Compas B. E. Coping with family conflict and economic strain: the adolescent perspective. J Res Adolesc 2002; 12: 243-74.

34. Kim K. J., Conger R. D., Elder G. H. Jr, Lorenz F. O. Reciprocal influences between stressful life events and adolescent internalizing and externalizing problems. Child Dev 2003; 74: 127-43.

35. Hanson M. D., Chen E. Socioeconomic status and health behaviors in adolescence: a review of the literature. J Behav Med 2007; 30: 263-85.

36. Finkelstein D. M., Kubzansky L. D., Goodman E. Social status, stress, and adolescent smoking. J Adolesc Health 2006; 39: 678-85.

37. Goodman E., Huang B. Socioeconomic status, depressive symptoms, and adolescent substance use. Arch Pediatr Adolesc Med 2002; 156: 448-53.

38. Gilman S. E., Rende R., Boergers J., Abrams D. B., Buka S. L., Clark M. A. et al. Parental smoking and adolescent smoking initiation: an intergenerational perspective on tobacco control. Pediatrics 2009; 123: e274-81.

39. Nagelhout G. E., de Korte-de B. D., Kunst A. E., van der Meer R. M., de Vries H., van Gelder B. M. et al. Trends in socioeconomic inequalities in smoking prevalence, consumption, initiation, and cessation between 2001 and 2008 in the Netherlands. Findings from a national population survey. BMC Public Health 2012; 12: 303.

40. Nagelhout G. E., Willemsen M. C., de Vries H. The population impact of smoke-free workplace and hospitality industry legislation on smoking behaviour. Findings from a national population survey. Addiction 2011; 106: 81623.

41. Fichtenberg C. M., Glantz S. A. Youth access interventions do not affect youth smoking. Pediatrics 2002; 109: 108892.

42. Hoffman B. R., Sussman S., Unger J. B., Valente T. W. Peer influences on adolescent cigarette smoking: a theoretical review of the literature. Subst Use Misuse 2006; 41: 10355. 